\title{
Methylene blue in SARS COV -2: Blue romance may be a solution of black tragedy
}

\author{
Seyyed Mohammad Ghahestani ${ }^{1}$ \\ ${ }^{1}$ Affiliation not available
}

April 30, 2020

\begin{abstract}
In previous publications the role of kininogen system has been postulated. On those publications the possible role of Icatibant, Ecallantide and Aprotinin in treatment of SARS Cov-2 has been raised. In this paper we raise the hypothetical potential of Methylene Blue in treatment of SARS COV 2. This medication may abort effects of Bradykinin by inhibition of NO Synthase inhibitor and promote oxygen saturation while it is inexpensive and ubiquitously accessible. Clinical studies can not be over emphasized.
\end{abstract}

Ghahestani Seyyed Mohammad*1,Sara Karimi 2,Mohammad Hamidi Madani3

*1: ${ }^{1}$ Children Medical Center Hospital, Tehran University of Medical Sciences (TUMS), Tehran, Iran. Email: mgrosva@gmail.com.No:+989128491811

Address: Pediatric Urology Ward,Children Medical Centre Hospital ,Gharib St, Keshavarz Blvd,Tehran,Iran 2:Sara Karimi, Alborz University of Medical sciences. E mail:Sarakarimi1984@yahoo.com

No: +989133004032

3: Mohammad Hamidi Madani.Labbafinejad Hospital, Shahid Beheshti University of Medical Sciences(SBMU). Email:m.hamidimadani70@gmail.com Phone No:+989393898696

Abstract:

In previous publications the role of kininogen system has been postulated. On those publications the possible role of Icatibant, Ecallantide and Aprotinin in treatment of SARS Cov-2 has been raised. In this paper we raise the hypothetical potential of Methylene Blue in treatment of SARS COV 2. This medication may abort effects of Bradykinin by inhibition of NO Synthase inhibitor and promote oxygen saturation while it is inexpensive and ubiquitously accessible. Clinical studies can not be over emphasized.

Methylene Blue in SARS COV -2: Blue romance may be a solution of black tragedy.

Ghahestani Seyyed Mohammad*, Sara Karimi, Mohammad Hamidi Madani

*Tehran University of Medical Sciences(TUMS)

mgrosva@gmail.com

Since emergence and wide spread dissemination of SARS- COV-2 all efforts in the scientific community have been focused on understanding the pathophysiology of the disease, alongside all aspects of a global health problem and its complexities. More over the scientific community is trying to accelerate the velocity of knowledge dissemination beyond that of the virus transcontinental sweep over by various strategies of 
fast track, green open access and preprints. At the same time, we must try to avoid any enticement for exoneration in accuracy and methodological soundness of the studies.

In this paper we try to raise either a new or under noticed medication for this disease based on an in-press accepted manuscript of senior author of this manuscript and some other independent researchers.(1-3)

\section{Discussion:}

Hitherto three main territories of physio-pathogenesis of the virus have been targeted.

A)The virus and its mechanism of replication and envelope integrity which have been aimed as potential targets of antiviral drugs e.g. Remdesivir, Favipiravir and Kaletra.(4-7)

B) The receptor of the virus in the body, the most notorious of them known as ACE 2 which has been addressed by actually distracting the virus by a recombinant soluble ACE 2 product(8). The intriguing part of the story is that indigenous ACE2 is a functional receptor/enzyme in the body so as it can not be innocuously irreversibly antagonised with any means, without serious adverse consequences. $(9,10)$.

C)The immunologic cascade known to ensue in a phenomenon known as "cytokine storm" which has previously been observed in other viral diseases e.g. Influenza(11, 12)

The terminology "cytokine storm" may be misleading (and may be not) in conveying this implicit presumption as a "proved fact" that no cytokine or autacoid can be impeached as the starter or the main player of the game. This presumption has not been approved yet, although it may subsequently unveil as true.

Some authors including main author of this article preceded to raise theoretical pivotal role of kininogen system in SARS Cov-2 scenario.(2, 3) [ Reference(1) was in non-peer reviewed status] . In our article, we tried to imply that Kininogen system, may be not "a bean in the bean pot "of all the events of the disease. Our paper has been accepted in Iranian Journal of Allergy Asthma and Immunology (IJAAI as In-press publication.(13)

Whatsoever in our In-press paper we tried to substantiate the special clinical features of this disease with clinical tentative characteristics of the disease, Dry cough, Lung vascular leakage syndrome, ameliorating effect of zinc, deleterious role of ACEI and early drop in saturation. More un published and / or non-peer reviewed data are being propagated (14) ) to hypothesize mechanism of haemoglobin distraction from oxygen exchange.

In above mentioned papers about kininogen implication in SARS- COV-2 scenario, medications have been proposed: Icatibant as a B2 Bradykinin receptor antagonist, Ecallantide and Aprotinin.

All these medications have favourable and unfavourable profiles. Icatibant and Ecallantide which have formally been approved for treatment of hereditary angioedema, are classified as orphan drugs and are quite expensive and unavailable in many settings. Aprotinin on the other hand has received a black box warning due to hypersensitivity and its effects on coagulation system are somewhat concerning for clinicians(15).

It is noteworthy that none of these medications have been reported to be used in SARS COV-2 and yet there are no studies performed to prove pre requisites of these theories comprising assessment of Bradykinin levels in sampled lung tissue. As far we know that Bradykinin plasma level may not be trustworthy due to autacoid and transience nature of the molecule.

A re contemplation on mechanism of Bradykinin action in the body and literature search, led us to the notion that several Bradykinin functions were exerted Via NO, a factor previously named as Endothelial Derived Relaxation Factor(16). Having read the un-published theories about haemoglobin drop out of oxygen exchange process(14), the consideration of $\mathrm{NO}$ as an allosteric ligand of haemoglobin(17, 18) seems sound.

NO synthase inhibitors and remarkably Methylene Blue have been shown to neutralize effects of Bradykinin(19). There upon a ubiquitously available NO Synthase inhibitor, Methylene Blue may seem $(19,20)$ to be effective in impediment of disease process and promote haemoglobin recruitment and oxygen saturation. 
In comparison with Icatibant, regardless of price or availability, it is post receptor, does not induce complex cascade coagulopathies and while we know Bradykinin is unstable and may harbour in the lung as a trench, Methylene Blue may prevail all through the body and seize the affected haemoglobin. As a bona fide proximal kinin cascade adjoining hemostasis axis is least affected. All these speculations must be clinically assessed.

Interestingly there are reports of Methylene Blue role in COVID 19 story $(21,22)$. However these studies are considering Methylene Blue in context of Photo dynamic therapy which has been the nearest pre-existing scenario on the counter of clinicians yet (22)for treatment of other diseases and remarkably not Methylene Blue per se.

More over Methylene Blue has been deemed effective in sepsis in numerous reports $(23,24)$ and some vascular leakage syndromes(25) which supports our notion that Methylene Blue must not go un noticed as a potential treatment in advanced stages of SARS COV-2.

We can add that some direct antiviral effects have been reported for Methylene Blue (26) some focusing on photodynamic treatment. We have not meticulously explored these properties in our consideration yet to see whether it has any direct effect on this kind of RNA virus.

\section{Conclusion:}

We think that Methylene Blue as an inexpensive ubiquitously available medication, has a considerable potential to be considered in treatment of SARS COV2.

We did not have a rapid access to set-up of a clinical study and it was prudent to share the idea with scientific community as soon as possible in this special situation.

Paradoxical and unexpected effects have been observed in Methylene Blue administration in other diseases if not meticulously done. Adverse reaction may happen in patients with a history of serotonergic medications as anti- depressants which may specially be prevalent these days(27). So any clinical step must be taken cautiously. In the other hand we must know that we are in a scrambling global health emergency and too much obsessive methodology may leave us with many dead patients to treat at the end of the day.

1. van de Veerdonk F, Netea MG, van Deuren M, van der Meer JW, de Mast Q, Bruggemann RJ, et al. Kinins and Cytokines in COVID-19: A Comprehensive Pathophysiological Approach. 2020.

2. Tolouian R, Vahed SZ, Ghiyasvand S, Tolouian A, Ardalan M. COVID-19 interactions with angiotensinconverting enzyme 2 (ACE2) and the kinin system; looking at a potential treatment. Journal of Renal Injury Prevention. 2020;9(2).

3. Seyed-Mohammad Ghahestani M, Javad Mahmoudi P, Sakineh Hajebrahimi M, 4 , Amir-Babak SioofyKhojine D, PhD5,3,6* Hanieh Salehi-Pourmehr P, Fatemeh Sadeghi-Ghyassi P, et al. Bradykinin as a Probable Aspect in SARS-Cov-2 Scenarios: Is Bradykinin Sneaking out of Our Sight?

. Iranian journal of allergy asthma and immunology( In- Press publication). 2020.

4. Al-Tawfiq JA, Al-Homoud AH, Memish ZA. Remdesivir as a possible therapeutic option for the COVID19. Travel medicine and infectious disease. 2020.

5. Ko W-C, Rolain J-M, Lee N-Y, Chen P-L, Huang C-T, Lee P-I, et al. Arguments in favour of remdesivir for treating SARS-CoV-2 infections. International Journal of Antimicrobial Agents. 2020.

6. Cai Q, Yang M, Liu D, Chen J, Shu D, Xia J, et al. Experimental treatment with favipiravir for COVID-19: an open-label control study. Engineering. 2020.

7. Lim J, Jeon S, Shin H-Y, Kim MJ, Seong YM, Lee WJ, et al. Case of the index patient who caused tertiary transmission of COVID-19 infection in Korea: the application of lopinavir/ritonavir for the treatment of COVID-19 infected pneumonia monitored by quantitative RT-PCR. Journal of Korean medical science. 2020;35(6). 
8. Alhenc-Gelas F, Drueke TB. Blockade of SARS-CoV-2 infection by recombinant soluble ACE2. Kidney International. 2020.

9. Li W, Moore MJ, Vasilieva N, Sui J, Wong SK, Berne MA, et al. Angiotensin-converting enzyme 2 is a functional receptor for the SARS coronavirus. Nature. 2003;426(6965):450-4.

10. Santos R, Ferreira AJ, Verano-Braga T, Bader M. Angiotensin-converting enzyme 2, angiotensin-(1-7) and Mas: new players of the renin-angiotensin system. J endocrinol. 2013;216(2):R1-R17.

11. Liu Q, Zhou Y-h, Yang Z-q. The cytokine storm of severe influenza and development of immunomodulatory therapy. Cellular \& molecular immunology. 2016;13(1):3-10.

12. Tisoncik JR, Korth MJ, Simmons CP, Farrar J, Martin TR, Katze MG. Into the eye of the cytokine storm. Microbiol Mol Biol Rev. 2012;76(1):16-32.

13. Seyed-Mohammad Ghahestani M, Javad Mahmoudi P, Sakineh Hajebrahimi M, 4, Amir Babak Sioofy Khojine D, PhD5,3,6* Hanieh Salehi-Pourmehr P, Fatemeh Sadeghi-Ghyassi P, et al. Bradykinin as a Probable Aspect in SARS-Cov-2 Scenarios: Is Bradykinin Sneaking out of Our Sight?. Iranian journal of allergy asthma and immunology( In- Press publication). 2020.

14. Read R. Flawed methods in "COVID-19: Attacks the 1-Beta Chain of Hemoglobin and Captures the Porphyrin to Inhibit Human Heme Metabolism". 2020.

15. Siehr S, Stuth E, Tweddell J, Hoffman G, Troshynski T, Jones D, et al. Hypersensitivity reactions to aprotinin re-exposure in paediatric surgery. European journal of cardio-thoracic surgery. 2010;37(2):307-11.

16. Linz W, Wohlfart P, Schölkens BA, Malinski T, Wiemer G. Interactions among ACE, kinins and NO. Cardiovascular research. 1999;43(3):549-61.

17. Huang Z, Shiva S, Kim-Shapiro DB, Patel RP, Ringwood LA, Irby CE, et al. Enzymatic function of hemoglobin as a nitrite reductase that produces NO under allosteric control. The Journal of clinical investigation. 2005;115(8):2099-107.

18. Kim-Shapiro DB, Schechter AN, Gladwin MT. Unraveling the reactions of nitric oxide, nitrite, and hemoglobin in physiology and therapeutics. Arteriosclerosis, thrombosis, and vascular biology. 2006;26(4):697-705.

19. Rhaleb N-E, Dion S, Barabé J, Rouissi N, Jukic D, Drapeau G, et al. Receptors for kinins in isolated arterial vessels of dogs. European journal of pharmacology. 1989;162(3):419-27.

20. Mayer B, Brunner F, Schmidt K. Inhibition of nitric oxide synthesis by methylene blue. Biochemical pharmacology. 1993;45(2):367-74.

21. Yu B, Jin C, Zhang J, Wu H, Zhou X, Yao H, et al. Methylene blue photochemical treatment as a reliable SARS-CoV-2 plasma virus inactivation method for blood safety and convalescent plasma therapy for the COVID-19 outbreak. 2020.

22. Henry M, Summa M, Patrick L, Schwartz L. A cohort of cancer patients with no reported cases of SARS-CoV-2 infection: the possible preventive role of Methylene Blue. Substantia. 2020:888-.

23. Galili Y, Kluger Y, Mianski Z, Iaina A, Wollman Y, Marmur S, et al. Methylene blue-a promising treatment modality in sepsis induced by bowel perforation. European surgical research. 1997;29(5):390-5.

24. Kwok ES, Howes D. Use of methylene blue in sepsis: a systematic review. Journal of intensive care medicine. 2006;21(6):359-63.

25. Umbrello M, Gardinali M, Ottolina D, Zanforlin G, Iapichino G. Systemic capillary leak syndrome: is methylene blue the silver bullet? Case reports in critical care. 2014;2014.

26. Floyd RA, Schinazi RF. Antiviral therapy using thiazine dyes. Google Patents; 2002. 
27. Hencken L, To L, Ly N, Morgan JA. Serotonin syndrome following methylene blue administration for vasoplegic syndrome. Journal of cardiac surgery. 2016;31(4):208-10. 